\title{
ACONTECIMENTOS NO TEMPO CRÔNICO ESTATIVO DE ÉMILE BENVENISTE: O SURGIMENTO DA INFÂNCIA E DO JOGO EDUCATIVO
}

\author{
Events in Time of Chronic Stative Émile Benveniste: \\ The Emergence of Childhood and Educational Game
}

\begin{abstract}
Michel Mendes, Morgana Bozza, Luís César Minozzo y Francisco Catelli
(UCS, Brasil)

Roniere dos Santos Fenner y Marcelo Prado Amaral Rosa
\end{abstract}

(UFRGS, Brasil)

\begin{abstract}
Resumo
O objetivo do artigo é articular a categoria do tempo crônico de Benveniste e sua condição estativa ao surgimento da infância e do jogo educativo, situando-os como acontecimentos essenciais para novas concepções de ser humano e de recurso educacional. Foi desenvolvido tendo como referenciais: i) o surgimento do jogo educativo de Rabecq-Maillard; ii) o surgimento da infância preconizado por Neil Postman; e iii) as três categorias de tempo de Émile Benveniste. A discussão recai sobre a categoria de tempo crônico de Benveniste. Ao final, destaca-se a relevância das noções de tempo e suas delimitações para a vida social.
\end{abstract}

Palavras-chave: Categorias de tempo; Jogo educativo; Infância.

\begin{abstract}
The objective of this article is to articulate the category of chronic time Benveniste and his condition the stand to the emergence of childhood and educational game, placing them as key events for new conceptions of human and educational resource. It was developed having as reference: i) the emergence of the educational game RabecqMaillard; ii) the emergence of childhood advocated by Neil Postman; and iii) the three categories of time Émile Benveniste. The discussion falls on the category of chronic Benveniste time. Finally, there is the relevance of notions of time and its boundaries for social life.
\end{abstract}

Keywords: Categories of Time | Educational Game | Childhood. 


\section{Considerações iniciais}

As discussões sobre o tempo sempre instigaram o ser humano. Porém, poucos seguiram os estudos sobre o tempo da língua. Émile Benveniste foi um deles, famoso linguista francês a se dedicar aos estudos sobre as línguas indo-europeias, teoria da enunciação, entre outras temáticas.

Em 1966 e 1974 são lançados seus dois primeiros livros - Problemas de Linguística Geral I e Problemas de Línguística Geral II - os quais são comportos por diversos artigos, sem linearidade específica ou necessariamente vínculos entre capítulos. Em um desses artigos o autor discute e elabora categorias de tempo, que serão discutidas e articuladas a acontecimentos históricos.

Este ensaio é de cunho teórico e busca tecer relações entre três autores: Émile Benveniste, Rabecq-Maillard e Neil Postman, descrevendo acontecimentos temporais importantes, como o surgimento da infância e do jogo educativo.

Atualmente, a infância é compreendida como importante fase do desenvolvimento humano, firmando-se como principal fase da vida, pois é nesta etapa que o mundo se apresenta e as primeiras relações se estabelecem. É nessa mesma fase que jogos e brincadeiras tornam-se prazerosos e típicos instrumentos lúdicos e educativos.

Utilizou-se como aporte teórico o quarto capítulo da obra Problemas de linguística geral II, de Émile Benveniste, publicado em 1974. Nele, o autor determina as três categorias de tempo: i) físico do mundo; ii) crônico; e iii) linguístico, que serão discutidas posteriormente. Como categoria de articulação para a discussão, propõe utilizar o tempo crônico e sua condição estativa, como meio para situar o surgimento da infância e do jogo educativo.

Os dois acontecimentos desenvolveram-se durante o século XVI, período de intensas transformações, como por exemplo, o renascimento. Portanto, utilizam-se os apontamentos de dois autores: o primeiro é da francesa Marie-Madeleine RabecqMaillard, que situa o surgimento do jogo educativo em sua obra Histoire des Jeux educatifs lançada em 1969, no mesmo período em que o segundo autor, o americano Neil Postman, determina o surgimento ou invenção da infância em sua obra $O$ desaparecimento da infância de 1982.

O objetivo do artigo é articular a categoria do tempo crônico de Benveniste e sua condição estativa ao surgimento da infância e do jogo educativo, situando-os como 
acontecimentos essenciais para novas ${ }^{4}$ concepções de ser humano e de recurso educacional.

Para tal, o artigo encontra-se dividido em duas seções. A primeira é intitulada Categorias de tempo de Benveniste, e busca apresentar as três categorias e condições do tempo. Na segunda seção, Acontecimento do tempo: o surgimento da infância e do jogo educativo são identificados dois relevantes momentos da história humana, articulando-os ao tempo crônico estativo, enquanto acontecimentos geradores de novas concepções.

\section{Categorias de tempo de Benveniste}

Em A linguagem e a experiência humana do livro Problemas de linguística geral II, lançado em 1974, Émile Benveniste elaborou e discutiu três categorias de tempo. Segundo o autor, em todas as línguas é comum encontrar categorias de expressão, que se situam de maneira constante. "As formas que revestem estas categorias são registradas e inventoriadas nas descrições, mas suas funções não aparecem claramente senão quando se estuda no exercício da linguagem e na produção do discurso.” (BENVENISTE, 1989, p. 68).

As categorias de tempo podem ser classificadas, como de pessoa e de tempo. Segundo Benveniste (1989), essas categorias são elementares, independentes da influência cultural, e por meio delas visualiza-se a experiência subjetiva de todos os sujeitos que se colocam em situações na e pela linguagem.

$\mathrm{O}$ autor acreditava que entre as formas linguísticas apresentadas pela experiência subjetiva, nenhuma seria tão rica como as que expressam o tempo. Nenhuma dessas seria tão difícil de explorar, devido à persistência de ideias concebidas à priori, das ilusões do bom senso e de possíveis armadilhas do psicologismo.

O tempo para Benveniste (1989) é vivo, recebe denominações diferentes. As denominações surgem conforme as representações humanas, variando conforme a cultura, sendo que a língua conceptualiza o tempo de maneira diferente da reflexão. "As línguas não nos oferecem de fato senão construções diversas do real, e é talvez justamente no modo pelo qual elas elaboram um sistema temporal complexo que elas são mais divergentes." (p. 70).

$4 \mathrm{O}$ uso da palavra nova, aqui assume o sentido de não existir até o momento, por isso é utilizada para indicar o surgimento. 
Com isso, Benveniste (1989) realiza a identificação de três categorias de tempo, sendo elas: i) físico do mundo; ii) crônico; e iii) linguístico.

A primeira é aquela uniforme, contínuo, e infinito. Apresenta correlato com o ser humano, variando de indivíduo para indivíduo e determinado pelas emoções e ritmos de vida.

A segunda é resultado do correlato psíquico do tempo físico do mundo. É entendido como o tempo dos acontecimentos, estando à vida humana nesse tempo, enquanto resultado de algum evento.

Por fim, a terceira categoria é aquela associada ao uso da fala, sua aplicação no discurso. "Uma coisa é situar um acontecimento no tempo crônico, outra coisa é inseri-lo no tempo da língua. É pela língua que se manifesta a experiência humana do tempo, e o tempo linguístico manifesta-se irredutível igualmente ao tempo crônico e ao tempo físico." (BENVENISTE, 1989, p. 74).

Para o autor, esse tempo deve receber um nome específico, pois difere substancialmente dos demais. Toda vez que o indivíduo empregar alguma forma gramatical do presente, estará assumindo sentido apenas para aquele momento. Já, em outro momento, o presente é reinventado, afinal, ele ainda não foi vivido. Essa é uma característica original da linguagem.

O tempo vivido pelo ser humano não apresenta possibilidade de retrocesso a um determinado momento, como a infância. Nem mesmo pode retroceder ao mesmo instante que acabou de ocorrer. "Nossa vida têm, portanto, pontos de referência que situamos exatamente numa escala reconhecida por todos, e aos quais ligamos nosso passado imediato ao longínquo." (BENVENISTE, 1989, p. 71). É nesse momento que se pode identificar a tríade temporal presente no autor: o passado, presente e futuro, assim descrito,

O observador, que é cada um de nós, pode lançar o olhar sobre os acontecimentos realizados, percorrê-los em duas direções, do passado ao presente ou do presente ao passado. Nossa própria vida faz parte destes acontecimentos, que nossa visão percorre numa direção ou em outra. Neste sentido, o tempo crônico, congelado na história, admite uma consideração bidirecional, enquanto nossa vida vivida [...] corre num único sentido. (BENVENISTE, 1989, p. 71). 
Conforme a descrição de tempo crônico, segundo Benveniste (1989), pode-se inferir que é no tempo crônico, que os acontecimentos se constroem, a continuidade do tempo dividida em eventos, como o surgimento da espécie humana, enquanto sequência temporal e biológica. Logo, “[...] os acontecimentos não são o tempo, eles estão no tempo. Tudo está no tempo, exceto o próprio tempo.” (BENVENISTE, 1989, p. 71).

Em todas as civilizações, as culturas apresentavam características em comum, para determinar o tempo crônico. Essa constante busca dos povos em situar-se no tempo é resultado intrínseco da necessidade humana básica de viver em sociedade para prosperar.

Por ser assim denominado (o tempo dos acontecimentos), o tempo crônico assume três condições fundamentais para a vida em sociedade: i) estativa; ii) diretiva; e iii) mensurativa.

Segundo Benveniste (1989), a primeira condição é considerada a do calendário. A contagem do tempo por meio do calendário permite identificar o marco inicial de uma cultura. O autor destaca a importância desse instrumento como regulador cultural. Tal modo oferece condições necessárias para determinar o que será seguido ou se acarretará alteração de direção para a comunidade. Exemplos de rumos tomados pelas sociedades na história humanidade são: o nascimento de Cristo (determinante para o início do calendário ocidental cristão), nascimento de Buda (ascensão de um grande representante), a fuga de Maomé (marca o início do calendário islâmico), entre outros acontecimentos.

A segunda condição, chamada de diretiva é decorrente da primeira (estativa). "Ela se enuncia pelos termos opostos 'antes.../depois...' relativamente ao eixo de referência." (BENVENISTE, 1989, p. 72). Exemplo dessa condição é a determinação utilizada para organizar o tempo em: a.C. e d.C., tendo como eixo de referência o nascimento de cristo.

E a última condição é a mensurativa, utilizada para denominar e determinar os intervalos que se apresentem de maneira constante, como os fenômenos naturais ligados ao cósmico. Exemplo dessa condição é "[...] o intervalo entre a aparição e o desaparecimento do sol em dois pontos diferentes do horizonte será o 'dia'; o intervalo entre duas conjunções da lua e do sol será o 'mês'; o intervalo definido por uma volta completa do sol e das estações será o 'ano'." (BENVENISTE, 1989, p. 72).

$\mathrm{Na}$ figura 1 pode-se situar em relação às três condições do tempo crônico, estabelecendo-se pontos e exemplos de referência, facilitando sua compreensão.

Figura 1 - Condições do tempo crônico 


\begin{tabular}{|l|l|l|l|}
\hline Condição & \multicolumn{1}{|c|}{ Estativa } & Diretiva & Mensurativa \\
Acontecimento & Marco inicial & Antes e depois & $\begin{array}{l}\text { Fenômenos } \\
\text { cósmicos }\end{array}$ \\
\hline Ponto de referência & $\begin{array}{l}\text { Nascimento de } \\
\text { Cristo }\end{array}$ & a.C. e d.C. & Rotação da Terra \\
\hline Exemplo & pelo autor, com basem Benveniste (1989). \\
\hline
\end{tabular}

Fonte: elaborado pelo autor, com base em Benveniste (1989).

São condições como as expostas acima que permitem o homem se localizar na história e posicionar-se de maneira objetiva aos acontecimentos. Segundo o autor, os intervalos são constantes, ou seja, o cômputo dos intervalos do tempo, ou dos acontecimentos é inalterável, proporcionando possíveis posicionamentos e comparações entre culturas. Caso contrário, por exemplo, “[...] se os anos mudassem com os dias, ou se cada um os contasse à sua maneira, nenhum discurso sensato poderia mais ser mantido sobre nada e a história inteira falaria a linguagem da loucura." (BENVENISTE, 1989, p. 73).

\section{Acontecimento do tempo: o surgimento da infância e do jogo educativo}

A infância concebida nos modelos atuais, nem sempre esteve presente na sociedade. Podese dizer que ela "nunca existiu". Segundo Postman (1999), a infância teria sido inventada, assim como tudo o que rodeia a humanidade.

Por muitos séculos a infância foi apenas um período de provações, um nível a ser ultrapassado, para então chegar à vida em sociedade. Na Grécia antiga, conforme Cambi (1999), a infância não era pensada como um período com características especiais, tanto que o pai, muitas vezes, decidia o futuro da criança: se ela seria ou não abandonada. Quando criadas, as crianças sofriam graves situações de abandono, estando privadas de afetividade e cuidados básicos em relação à sua saúde, infanticídios, uso para rituais míticos, ou seja, a mercê da não concepção grega de infância para esse período.

A infância cresce em casa, controlada pelo "medo do pai", atemorizada por figuras míticas [...] gratificada com brinquedos [...] e entretida pelos jogos, mas sempre colocada à [sic] margem da vida social. Ou então por esta brutalmente 
corrompida, submetida à violência, a estupro, a trabalho, e até a sacrifícios rituais. (CAMBI, 1999, p. 82).

No império romano a situação não mudou muito. Porém, na Idade Média, segundo Postman (1999), os romanos são os primeiros a iniciar uma distinção entre criança e adulto, por meio do cuidado em distinguir o que poderia ou não ser dito às crianças, surgindo um sentimento de "vergonha" em relação aos segredos dos adultos.

Em um de seus comentários sobre educação, Quintiliano critica as posturas assumidas por seus convidados ou pares diante das crianças nobres, conforme descreve:

Nós nos deliciamos se elas dizem alguma coisa inconveniente, e palavras que não toleraríamos vindas dos lábios de um pajem alexandrino são recebidas com risos e um beijo. [...] [sic] elas nos ouvem dizer tais palavras, vêem nossas amantes e concubinas; em cada jantar ouvem ressoar canções obscenas, e são apresentadas a seus olhos coisas das quais deveríamos nos ruborizar ao falar. (DEMAUSE, 1974, p. $45^{5}$ apud POSTMAN, 2011, p. 23).

A educação das crianças nunca foi um assunto privilegiado ou digno de discussões. Essas ideias emergiam de pensadores influentes que foram, aos poucos identificando necessidades para essa, até então desconhecida, etapa do desenvolvimento humano. Uma delas referia-se a utilização de instrumentos para a educação das crianças, como a ludicidade por meio do jogo, destacada por Pestalozzi e Froebel (ARCE, 2002; KISHIMOTO, 1994).

Porém, durante a Idade Média, segundo Ariès (1981), a Igreja Católica comandava os rumos da sociedade, inclusive da educação. Nesse sentido, a ordem religiosa dominante identificou no jogo, um caráter pecaminoso, não digno do ser humano, passando a considerá-lo semicriminoso, em sua maioria.

Com o avançar dos séculos, a Idade Moderna surge e com ela transformações sociais, educacionais e políticas. Um dos movimentos que marcou o período foi o Renascimento. "A visão antropocêntrica do Renascimento, a partir do século XIV, influenciou para que o jogo, gradativamente, fosse retirado da reprovação oficial e incorporado ao processo de formação de crianças e jovens.” (LIMA, 2008, p. 15).

A partir do século XVI, os humanistas identificam possibilidades educativas no jogo. No entanto, conforme Ariès (1981), o passo primordial é dado pelo aparecimento da

5 DEMAUSE, Lloyd. The evolution of childhood. In: Psychohistory Press, 1974. The history of childhood. New York: The 
Companhia de Jesus, liderada por Ignácio de Loyola $\left(1491\right.$ - 1556) ${ }^{6}$, e pela implantação dos colégios jesuítas que por meio de esforços impuseram na população, a percepção contrária à pregada no período anterior em relação aos jogos.

Os padres compreenderam desde o início que não era nem possível nem desejável suprimi-los, ou mesmo fazê-los depender de permissões precárias e vergonhosas. Ao contrário, propuseram-se a assimilá-los e a introduzi-los oficialmente em seus programas e regulamentos, com a condição de que pudessem escolhê-los, regulamentá-los e controlá-los. Assim, disciplinados, e considerados a partir de então como meios de educação tão estimáveis quanto os estudos. (ARIĖS, 1981, p. 65).

Um novo sentimento surge. Segundo Ariès (1981), o jogo passa a ser incorporado pela educação, fato que até então fora considerado inapropriado pela ordem religiosa dominante. É nesse momento histórico que a francesa Rabecq-Maillard identifica o surgimento do jogo educativo. "Jogos educativos são aqueles que, sob forma lúdica e aparentemente desinteressada, pelo menos para quem participa deles, têm por finalidade a educação do indivíduo.” (RABECQ-MAILLARD, 1969, p. 2 citado por VANZELLA, 2009, p. 18).

Nesse mesmo momento histórico, segundo Postman (2011), a infância como estrutura social teria surgido. Surgem também os livros impressos, provocando a distinção entre essas duas etapas, baseadas na “[...] competência de leitura.”, dos adultos e na emergente infância, caracterizada pela “[...] incompetência de leitura.” (p. 32).

O impacto causado pela prensa tipográfica rompe com o entendimento de infância dos países europeus, que delimitava a "infância" até os sete anos e a idade adulta iniciava imediatamente, sem uma fase intermediária. Até esse momento, apenas os adultos sabiam e podiam ler. (POSTMAN, 2001).

Traços do pensamento da época podem ser identificados na figura 2, como a não diferenciação da criança e do adulto. A criança era vista como um mini-adulto, a linguagem e os jogos eram os mesmos, tanto para criança, como para adulto, conforme detalhes da imagem.

Figura 2 - Jogos infantis, obra de Pieter Bruegel (1560).

6 Por ter sido militar incrementou o uso dos jogos ginásticos nos colégios Jesuítas. Acreditavam que os jogos serviam como uma educação para o corpo, e chegaram a publicar tratados de ginásticas em Latim, contendo regras e informações necessárias aos jogos recomendados. 


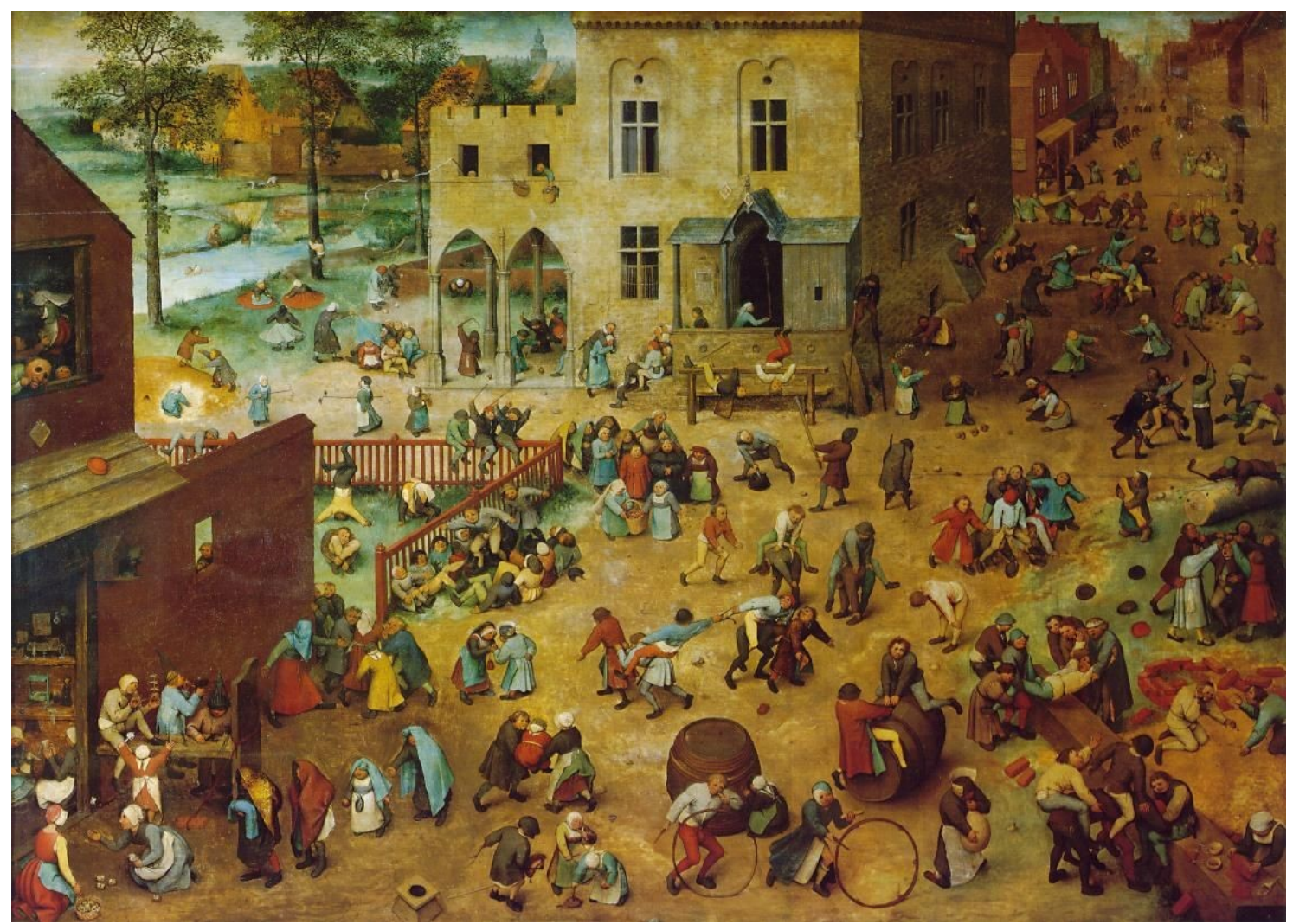

Fonte: https://resenhasdefilosofia.files.wordpress.com/2013/o3/brincadeirasbruegel.jpg

A obra representa de modo característico o ideal do momento histórico-cultural que a civilização humana vivia. Muitas interpretações e estudos foram realizados a partir dessa pintura por Amado (19987 citado por ALMEIDA, 2012) e Netto, Perassi, Fialho (2013), chegando a ser identificados de 200 a 250 personagens e aproximadamente 80 a 84 atividades diferentes, como brincadeiras e jogos.

Acredita-se que possa haver relações para o aparecimento do jogo educativo como elemento essencial para a infância. Uma vez que sendo à criança percebida como ser pertencente à sociedade, ela demandaria de instrumentos que estimulassem, despertassem e aprimorassem suas capacidades físicas e intelectuais. A partir desse momento, a infância passa a ser concebida como tal, a visão diminuta de ser humano é rompida, e a concepção de indivíduo com características próprias impera.

De acordo com a descrição anteriormente realizada, destacou-se as categorias do tempo: i) físico do mundo; ii) crônico; e iii) linguístico, além das três condições essenciais no tempo crônico: i) estativa; ii) diretiva; e iii) mensurativa. A primeira condição é a

7 AMADO, João. Brincar, aos olhos de Brueghel. In: N. Pais e L. Santos (Org.). Cultura lúdica, tradição e modernidade. (p. 25-35). Cadernos de atividade lúdica, nº 1. Lisboa: Instituto de Apoio à Criança, 1998. 
articuladora da discussão, possibilitando situar no tempo importantes acontecimentos, como o surgimento da infância e do jogo educativo, afinal, essa é sua característica.

Esse marco na história humana concebe a sociedade uma nova visão sobre a infância, ele indica um período do desenvolvimento humano repleto de peculiaridades, que o tornam único. O mesmo ocorre com o jogo. Passa a ser visto com potencial educacional, em especial para as crianças. Posteriormente, grandes pensadores como Pestalozzi, Froebel, Montessori e outros, apontariam o jogo como essencial para o desenvolvimento infantil, assumindo um caráter decisivo na educação das crianças.

\section{Considerações finais}

A história humana é repleta de acontecimentos, porém alguns apenas marcam o período histórico, enquanto que outros transformam pensamentos e situam no tempo "momentos de transgressão temporal”. Com o surgimento da concepção de infância e do jogo educativo no século XVI, a civilização moderna cria um "calendário" para a educação humana. Como resultado para esses dois acontecimentos, surge à necessidade de uma educação específica, principalmente voltada para a aprendizagem da leitura, algo que privou as crianças até os sete anos de idade.

Pode-se situar a modernidade como um novo momento para a vida em sociedade, definindo características e condições próprias para a educação infantil, firmando no tempo crônico estativo sua nova visão, seus novos rumos. Junto com ele, surge a necessidade de um novo tempo, um tempo linguístico apropriado a educação das crianças, e não somente a ela.

Um dos grandes desafios da educação básica é posicionar-se no tempo dos estudantes. O momento do emergir é passado, marcou o calendário educacional infantil e projetou seus novos degraus. O que o presente demanda é de um tempo vivo, atualizado, envolvido com seus acontecimentos, afinal "[...] os acontecimentos não são o tempo, eles estão no tempo.” (BENVENISTE, 1989, p. 71).

\section{Referências bibliográficas}

ALMEIDA, Marcos Teodorico Pinheiro de. O brincar das crianças em espaços públicos. 2012. 450 f. Tese (Doutorado) - Curso de Programa de Doctorado: Diversidad y 
Cambio En Educación: Políticas y Prácticas, Departamento de Didáctica y Organización Educativa, Universitat de Barcelona, Barcelona, 2012. Disponível em: <http://www.tesisenred.net/bitstream/handle/10803/96172/01.MTPA_TESE.pdf?>. Acesso em: 20 ago. 2015.

ARCE, Alessandra. Friedrich Froebel: o pedagogo dos jardins de infância. Petrópolis, RJ: Vozes, 2002. 117 p. (Educação e conhecimento).

ARIÈS, Philippe. História Social da Criança e da Família. 2. ed. Rio de Janeiro: LTC, 1981. 196 p. Tradução: Dora Flaksman.

BENVENISTE, Émile. Problemas de linguística geral II. Campinas/SP: Pontes, 1989. 294 p. Tradução: Eduardo Guimarães, et al.

CAMBI, Franco. História da pedagogia. São Paulo: UNESP, 1999. 701 p. Tradução: Álvaro Lorencini.

KISHIMOTO, Tizuko Morchida. O jogo e a educação infantil. São Paulo: Pioneira, 1994. 63 p. (A Pré-Escola Brasileira).

LIMA, José Milton de. 0 jogo como Recurso Pedagógico no Contexto Educacional. São Paulo: Unesp, 2008. 157 p.

NETTO, Marinilse; PERASSI, Richard; FIALHO, Francisco Antonio Pereira. Estudos semióticos: análise perceptiva e a terceiridade peirceana na obra "Jogos Infantis" de Pieter Bruegel. Projetica, Londrina, v. 4, n. 1, p.249-266, 3 jun. 2013. Universidade Estadual de Londrina. $\quad$ DOI: 10.5433/2236-2207.2013v4n1p249. Disponível em: $<$ http://www.uel.br/revistas/uel/index.php/projetica/article/view/15541/13430>. Acesso em: 20 ago. 2015.

POSTMAN, Neil. O desaparecimento da infância. Rio de Janeiro: GRAPHIA, 2011. $190 \mathrm{p}$.

VANZELLA, Lila Cristina Guimarães. O jogo da vida: Usos e significações. 2009. 218 f. Tese (Doutorado) - Curso de Faculdade de Educação, Programa de PósGraduação em Educação, Universidade de São Paulo, São Paulo, 2009. Disponível em: $\quad<$ http://www.teses.usp.br/teses/disponiveis/48/48134/tde-02092009160733/pt-br.php>. Acesso em: 13 jul. 2015. 